\title{
CAUSES OF AUTOIMMUNE HEMOLYTIC ANEMIA AND ITS CLINICAL PRESENTATION.
}

1. MBBS, M.Phil

Assistant Professor Hematology Pathology

Akhtar Saeed Medical and Dental College, Lahore.

2. MBBS, M.Phil

Senior Demonstrator Pathology University College of Medicine \& Dentistry, University of Lahore.

3. MBBS, M.Phil

Assistant Professor Hematology Shaikh Zayed Postgraduate Medical Institute,

Shaikh Zayed Medical Complex, Lahore.

4. MBBS, M.Phil

Consultant Pathologist \& Hematologist

Jinnah Burn Center, Jinnah Hospital Lahore.

5. MBBS, M.Phil

Assistant Professor Hematology Pathology

Nishtar Medical University, Multan.

Correspondence Address:

Dr. Umme Habiba

Department of Pathology

Akhtar Saeed Medical and Dental

College, Lahore.

umme.habibah2009@gmail.com

Article received on:

29/07/2019

Accepted for publication:

$31 / 10 / 2019$

\begin{abstract}
Umme Habiba1, Anam Ilyas², Farwa Sijjeel ${ }^{3}$, Ghazala Tabassum ${ }^{4}$, Sabeen Fatima ${ }^{5}$
\end{abstract}
ABSTRACT... Objectives: To evaluate various causes of autoimmune hemolytic anemia and its presenting signs and symptoms. Study Design: Cross sectional study. Setting: Fatima Jinnah Medical College Lahore. Period: November 2018 to April 2019. Material \& Methods: In this study 90 cases were included having age range of 14-75 years with mean age of 46.5 year with the possibility of autoimmune hemolytic anemia (AIHA). Screening test used for evaluating AlHAin this study include Direct and Indirect Antiglobulin Tests and Cold Agglutinin Titer (CAT). All relevant data was documented properly. Results: Total 90 cases were included in the study comprising on $71 \%$ female and $29 \%$ male cases. $22.2 \%$ cases were having primary and $77.8 \%$ were having secondary autoimmune hemolytic anemia. Most common presenting complaint was generalized body weakness in $25(27.7 \%)$ cases and on examination most common finding was splenomegaly in $30(33.3 \%)$ cases. Hemoglobin was less than $8 \mathrm{~g} / \mathrm{dl}$ in $28(31 \%)$ cases. Direct Antiglobulin test was positive in $64(71 \%)$ cases, DAT and IATboth were found to be positive in 22(24.4\%) cases and DAT and CAT both found positive in $4(4.4 \%)$ cases. Blood transfusion was done in $28 \%$ cases having severe anemia. Most common cause of autoimmune hemolytic anemia found among study group patients was connective tissue disorder in $25(27.8 \%$ ) cases. P-value less than 0.05 were considered significant and more than 0.05 was non-significant. Conclusion: In our study autoimmune hemolytic anemia was mostly found in female population with most common presentation of generalized body weakness, pallor of hands, hepatosplenomegaly and severe anemia. Most common cause found of AlHA was connective tissue disorders.

Key words: $\quad$ Autoimmune Hemolytic Anemia, Direct Antiglobulin Test, Indirect Antiglobulin Test, Cold Agglutinin Titer, Causes of Anemia.

Article Citation: Habiba U, Ilyas A, Sijjeel F, Tabassum G, Fatima S. Causes of autoimmune hemolytic anemia and its clinical presentation. Professional Med J 2020; 27(4):831-835. DOI: 10.29309/TPMJ/2020.27.04.3983

\section{INTRODUCTION}

Autoimmune hemolytic anemia is a disorder in which a specific type of antibodies is produced in the body which attaches to the surface of RBCs and cause their hemolysis early leading to development of anemia. Direct Antiglobulin Test is used to diagnose it. It is a rare type of disease. Still here are no proper guidelines for its treatment based on evidence. ${ }^{1}$ According to a study DAT found negative in $3-11 \%$ of cases hence requiring any other specialized test to diagnose this disease. ${ }^{2}$ All over the world its incidence is $1-3 \%$ in 100,000 populations. ${ }^{3}$ Diagnosis of AlHA is made on the basis of clinical signs symptoms and laboratory findings such as anemia, increased serum level of bilirubin (indirect), low serum level of Haptoglobin and elevated serum Lactate dehydrogenase level. There is positive comb test (DAT test). In making diagnosis of AlHA we should rule out its hereditary and other causes as well. ${ }^{4}$ AlHA is of two types on the basis of etiology primary and secondary. Primary AIHA is due to idiopathic causes and secondary AlHA is due to some underlying cause. Steroids play major role in the treatment of AlHA.,5 In such patients warm antibodies ( $\lg G$ ) are present in the blood which attach to RBCs surface and cause their opsonization. Other antibodies present are cold agglutinin (IgM) and Donath-Landsteiner antibodies (a type of $\mathrm{lgG}$ ). Direct Antiglobulin Test detects antibodies on the surface of RBCs during hemolysis while Indirect Antiglobulin Test 
detects free antibodies in the blood. This study is very important because many patients present with anemia and they are transfused with whole blood frequently not knowing the real cause of anemia. This study helps in making diagnosis of the patients having AlHA and helps in finding its cause as well. Our purpose of study was to determine findings in patients having AlHA presenting to a tertiary care hospital.

\section{MATERIALS AND METHODS}

This is a cross sectional study of descriptive type, conducted in Fatima Jinnah Medical College Lahore. Study was started in November 2018 and completed in April 2019 comprising on total duration of 6 months.

All cases in study group gave written consent. Permission was taken from ethical committee of the institution as well. We included 90 cases in this study which were reported in pathology department for evaluation of autoimmune hemolytic anemia. A proforma was designed in which data of the patients was documented such as age, sex, demographic data, presenting signs and symptoms, positive findings in history and physical examination. These cases were screened for AlHA by Direct Antiglobulin Test, Indirect Antiglobulin Test and Cold Agglutinin Titer. An inclusion and exclusion criteria was designed according to which all those cases were included in this study which showed positive Direct Antiglobulin Test. Pregnant ladies, history of blood transfusion in previous three months or patients having $\mathrm{RH}-\mathrm{ABO}$ incompatibility in newborns also show DAT positive but they were excluded from this study. In DAT, gel card technique was used by DiaMedID cards with polyspecific antihuman globulin. Parameters from different pathological laboratories were correlated such as hemoglobin level, reticulocyte count, peripheral blood morphology, total leucocyte count and differential leucocyte count. Further investigations of cases included serum lactate dehydrogenase level, Haptoglobin level, serum indirect bilirubin level, serum RA factor, ANA level, moreover renal and liver function tests were also done for evaluating any complication or organ failure.

\section{RESULTS}

Total 90 cases were included in the study comprising on $64(71 \%)$ female and $26(29 \%)$ male cases. Primary AIHA was found in 20(22.2\%) cases and secondary AlHA was found in 70(77.8\%) cases. Presenting complaints of patients with primary AlHA included generalized weakness in $7(35 \%)$ cases, pallor of face and extremities $4(20 \%)$, dyspnea $3(15 \%)$, fever $2(10 \%)$, joint pain and abdominal pain in $1(5 \%)$ and $2(10 \%)$ cases respectively. Frequency of same complaints in cases with secondary AlHA were as generalized weakness in $18(25.7 \%)$, pallor in $10(14.3 \%)$, breathlessness 11(15.7), fever $9(12.8 \%)$, joint and abdominal pain in $12(17.14 \%)$ and $3(4.3 \%)$ cases respectively.

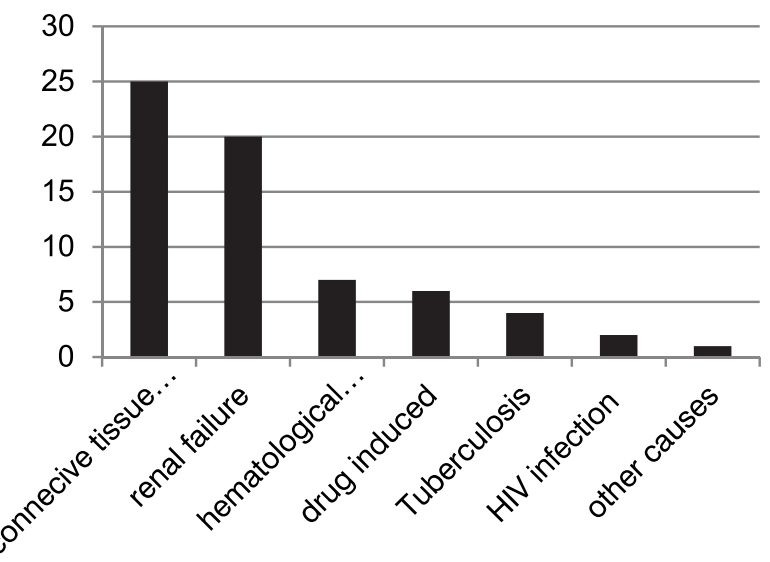

Figure-1. Causes of AlHA among patients in study group $(\mathrm{N}=90)$

Primary AlHA has idiopathic cause. Causes of secondary AlHA included connective tissue disorders in $25(27.8 \%)$, renal failure in $20(22.2 \%)$, hematological disorders in $7(7.8 \%)$, hematological malignancies in 5(5.6\%), drug induced AlHA in $6(6.7 \%)$, tuberculosis was found as a cause of AlHA in 4(4.4\%), HIV infection in 2(2.2\%) and miscellaneous causes found in one case.

On physical examination in patients with primary AlHA, splenomegaly was found in $10(50 \%)$, hepatosplenomegaly in $4(20 \%)$, only hepatomegaly in $3(10 \%)$ cases, lymphadenopathy in $1(10 \%)$ cases and no visceromegaly at all in $2(20 \%)$ cases. Findings on physical examination in patients with secondary AIHA noticed were: splenomegaly alone in $20(28.5 \%)$ cases, 
hepatosplenomegaly in $15(21.5 \%)$, hepatomegaly alone in $8(11.4 \%)$ cases, lymphadenopathy in $9(12.9 \%)$ and no visceromegaly found in $18(25.7 \%)$ cases.

Patients with primary AlHA were having severe anemia (HB less than $7 \mathrm{~g} / \mathrm{dl}$ ) in $8(40 \%)$ cases, moderate anemia (HB 7-10 g/dl) in 6(30\%) cases and mild anemia (HB 10-12g/dl) was found in just one case. Similarly in patients group with secondary AlHA severe anemia was found in $20(28.6 \%)$ cases, moderate anemia in $35(50 \%)$ cases and mild anemia in $9(12.8 \%)$ cases.

\begin{tabular}{|c|c|c|c|c|c|}
\hline \multirow[t]{2}{*}{ Presenting Complaints } & \multicolumn{2}{|c|}{ Primary AlHA $(n=20)$} & \multicolumn{2}{|c|}{ Secondary AIHA $(n=70)$} & \multirow{2}{*}{$\begin{array}{r}\text { P-Value } \\
0.152\end{array}$} \\
\hline & $\mathbf{N}$ & $\begin{array}{l}\text { Percentage } \\
(\mathrm{N} / 20)\end{array}$ & $\mathbf{N}$ & $\begin{array}{l}\text { Percentage } \\
(\mathrm{N} / 70)\end{array}$ & \\
\hline Fever & 2 & $10 \%$ & 9 & $12.8 \%$ & 0.114 \\
\hline Pallor of face & 4 & $20 \%$ & 10 & $14.3 \%$ & 0.169 \\
\hline Abdominal Pain & 2 & $10 \%$ & 3 & $4.3 \%$ & 0.518 \\
\hline $\begin{array}{l}\text { Bleeding from Gums and } \\
\text { body orifices }\end{array}$ & 1 & $5 \%$ & 7 & $10 \%$ & 0.352 \\
\hline Breathlessness & 3 & $15 \%$ & 11 & $15.7 \%$ & 0.071 \\
\hline
\end{tabular}

Table-I. Presenting complaints of patients in study group having Autoimmune Hemolytic anemia

\begin{tabular}{|c|c|c|c|c|c|}
\hline \multirow[t]{2}{*}{ Antiglobulin Test } & \multicolumn{2}{|c|}{ Primary AIHA } & \multicolumn{2}{|c|}{ Secondary AlHA } & \multirow{2}{*}{ P-Value } \\
\hline & $\mathbf{N}$ & Percentage(N/20) & $\mathbf{N}$ & Percentage(N/70) & \\
\hline DAT & 11 & $55 \%$ & 53 & $75.7 \%$ & 0.155 \\
\hline $\mathrm{DAT}+\mathrm{CAT}$ & 3 & $15 \%$ & 1 & $1.4 \%$ & 0.084 \\
\hline Total & 20 & $22.2 \%$ & 70 & $77.8 \%$ & \\
\hline
\end{tabular}

Serological findings in patients with primary AIHA were positive DAT (Direct Antiglobulin Test) in $11(55 \%)$ cases, DAT and IAT (Indirect Antiglobulin Test) positive in $6(30 \%)$ cases and DAT and CAT (cold agglutinin test) both positive in 3(15\%) cases while serological results in patients with secondary AlHA were positive DAT in 53(75.7\%) cases, DAT and IAT positive in $16(22.8 \%)$ cases and DAT and CAT positive in 1(1.4\%) case.

\section{DISCUSSION}

In this study we determined various signs and symptoms and laboratory findings in patients presenting to a tertiary care setup having autoimmune hemolytic anemia. Total 90 cases were studied. In AlHA RBCS are destroyed by auto antibodies leading to development of anemia. According to a study conducted in Croatia on 56 patients, 25\% were having primary AlHA and $75 \%$ were having secondary causes of anemia.
These results are very close as compared to our study in which $22 \%$ cases were having primary and $78 \%$ were having secondary AlHA. ${ }^{7}$ Few studies have shown that flow cytometry is more sensitive to DAT and can detect low quantity of antibodies in the blood and can help in diagnosis AIHA. DAT many times give false negative results as it can't detect low quantity of immunoglobulin and diagnosis is missed so in this regard flow cytometry is suitable investigation. ${ }^{8}$ There are various secondary causes of AlHA and tumors are one of them. Surgical excision of tumors can treat anemia and in these cases medical treatment has no significant role. ${ }^{9}$ Other causes of secondary AlHA include connective tissue disorders, renal failure, hematological disorders, hematological malignancies, drug induced, associated with other infectious diseases such as tuberculosis and HIV infection. Tuberculosis causes increased production of $\lg G$ and $\lg M$ 
antibodies and can cause Warm agglutinin, Cold agglutinin or mixed type AlHA. ${ }^{10}$ Steroids therapy is very effective in AlHA and few studies have shown that steroid reduce hemolysis and hence improves hemoglobin without transfusion of blood while transfusion is needed in severe anemia. Intravenous use of immunoglobulins also show good results according to some studies and this can be used another treatment option along with steroid use. Steroids are effective against warm antibodies AlHA while in cold antibodies AlHA its role is very limited and in these cases intravenous immunoglobulin play significant role. ${ }^{11,12}$ In our study primary AlHA was found in $22 \%$ cases and secondary AlHA was found in $77 \%$ cases that is comparable to a study in which $46 \%$ cases were having primary AlHA. This percentage is much high than our study but that can be change due to demographic and ethnicity difference. ${ }^{13,14}$ According to a study conducted in a tertiary care hospital of France, anemia was present in 83\% cases and breathlessness and chest pain was presenting complaint in $9 \%$ cases, need for blood transfusion was in $52 \%$ cases with primary AIHA and $72 \%$ cases with secondary AlHA. These results are comparable to our study results with breathlessness in $15 \%$ cases and moderate to severe anemia was present in $69 \%$ cases, transfusion needed in $40 \%$ of cases with primary AIHA and $28.5 \%$ cases with secondary AlHA. ${ }^{15,16}$ Another study reported weakness and fatigue in all cases of study group, dyspnea in $53 \%$, jaundice in $41 \%$, abdominal pain in $41 \%$, pallor in $86 \%$ and hepatosplenomegaly in $44.2 \%$ cases. In our study abdominal pain was present in $5.5 \%$, splenomegaly was found in $33.3 \%$ and hepatomegaly was found in $12.2 \%$ cases.

\section{CONCLUSION}

Autoimmune hemolytic anemia is a rare disease and is frequently neglected or misdiagnosed. Mostly found in female population with most common clinical presentation of generalized body weakness, pallor and on examination hepatosplenomegaly is common finding. Secondary AIHA is more common than Primary AlHA. Steroids therapy play major role in initial treatment of it with excellent outcomes. Direct Antiglobulin Test is very helpful in diagnosing the patients with AIHA. Patients with primary AIHA are more anemic than the cases with secondary type of anemia.

Copyright@ 31 Oct, 2019.

\section{REFERENCES}

1. Chineke I, Kagbo-Kue S, Aniekwena J, Rose M. Successful treatment of severe idiopathic mixed autoimmune hemolytic anemia with bortezomib and intravenous immunoglobulin. Int $\mathrm{J}$ Blood Transfus Immunohematol. 2019; 9:100046Z02IC2019.

2. Miller J, Cai W, Andrews J, Narla A. A case series of pediatric patients with direct antiglobulin test negative autoimmune hemolytic anemia. Transfusion. 2019 May 21.

3. Jaime-Pérez JC, Rodríguez-Martínez M, Gómez-deLeón A, Tarín-Arzaga L, Gómez-Almaguer D. Current approaches for the treatment of autoimmune hemolytic anemia. Arch ImmunolTherExp (Warsz) 2013; 61:385-395.

4. Anguiano-Álvarez VM, Hernández-Company A, Hamdan-Pérez N, et al. Splenic myeloid metaplasia in warm autoimmune hemolytic anemia (wAIHA): A retrospective study. Blood Res 2018; 53:35-40.

5. Alonso HC, Manuel AV, Amir CG, et al. Warm autoimmune hemolytic anemia: Experience from a single referral center in Mexico City. Blood Res 2017; 52:44-49.

6. Roumier M, Loustau V, Guillaud C, et al. Characteristics and outcome of warm autoimmune hemolytic anemia in adults: New insights based on a single-center experience with 60 patients. Am J Hematol 2014; 89:E150-E155.

7. Williams P, Schwartz S, Lopez-Plaza I. An unusual case of autoimmune hemolytic anemia-thinking outside the box.

8. Khunger JM, Pati HP, Mahapatra M, Khunger A. Utilisation of Flow-cytometry in the diagnosis of auto immune haemolytic anaemia. Indian Journal of Hematology and Blood Transfusion. 2019 Apr 12; 35(2):297-303.

9. Alves MF, Leite JB, Neto ML, Vieira RP, Coelho JM, Macedo FB. A five-month-old infant with severe autoimmune hemolytic anemia treated without blood transfusions. Journal of Medical Cases. 2018 Aug 25; 9(9):284-6. 
10. Rathish D, Siribaddana S. Tuberculosis induced autoimmune haemolytic anaemia: A systematic review to find out common clinical presentations, investigation findings and the treatment options. Allergy, Asthma \& Clinical Immunology. 2018 Dec; 14(1):11.

11. Chineke I, Kagbo-Kue S, Aniekwena J, Rose M. Successful treatment of severe idiopathic mixed autoimmune hemolytic anemia with bortezomib and intravenous immunoglobulin. Int $\mathrm{J}$ Blood Transfus Immunohematol. 2019; 9:100046Z02IC2019.

12. Zanella A, Barcellini W. Treatment of autoimmune hemolytic anemias. Haematologica. 2014 Oct 1; 99(10):1547-54.

13. Lauda-Maillen M, Catroux M, Roy-Peaud F, SouchaudDebouverie O, El BM, Roblot P. Diagnosis and management of acquired immune haemolytic anaemia excluding neoplasia. Adequacy with the current guidelines published in 2009. La Revue de medecine interne. 2017 Oct; 38(10):648-55.
14. Bass GF, Tuscano ET, Tuscano JM. Diagnosis and classification of autoimmune hemolytic anemia. Autoimmunity reviews. 2014 Apr 1; 13(4-5):560-4.

15. Roumier M, Loustau V, Guillaud C, Languille L, Mahevas M, Khellaf M, Limal N, Noizat-Pirenne F, Godeau B, Michel M. Characteristics and outcome of warm autoimmune hemolytic anemia in adults: New insights based on a single-center experience with 60 patients. American journal of hematology. 2014 Sep; 89(9):E150-5.

16. Chaudhary RK, Das SS. Autoimmune hemolytic anemia: From lab to bedside. Asian journal of transfusion science. 2014 Jan; 8(1):5.

\begin{tabular}{|c|l|l|l|}
\hline \multicolumn{3}{|c|}{ AUTHORSHIP AND CONTRIBUTION DECLARATION } \\
\hline Sr. \# & \multicolumn{1}{|c|}{ Author(s) Full Name } & \multicolumn{1}{|c|}{ Contribution to the paper } & Author(s) Signature \\
\hline 1 & Umme Habiba & $\begin{array}{l}\text { Topic Selection and data } \\
\text { collection. } \\
\text { Data collection. }\end{array}$ \\
\hline 2 & Anam Ilyas & Data composing. \\
\hline 4 & Farwa Sijjeel & Gata collection. \\
\hline 5 & Sabeen Fatima & $\begin{array}{l}\text { Found additional resources of } \\
\text { information. }\end{array}$ \\
\hline
\end{tabular}

